\title{
KUALITAS JASA PELAYANAN TERHADAP KEPUASAN PASIEN RAWAT INAP DI PUSKESMAS LANCIRANG KECAMATAN PITU RIAWA KABUPATEN SIDENRENG RAPPANG
}

\author{
Mardiana \\ Fakultas IImu Sosial dan IImu Politik Universitas Muhammadiyah Sidenreng Rappang \\ Mardiana43152085.1b43@gmail.com
}

\begin{abstract}
Abstrak
Penelitian ini bertujuan untuk mengetahui kualitas jasa pelayanan terhadap kepuasan pasien rawat inap dan faktor-faktor yang memengaruhi kualitas jasa pelayanan terhadap kepuasan pasien rawat inap di Puskesmas Lancirang Kecamatan Pitu Riawa Kabupaten Sidenreng Rappang. Populasi penelitian ini adalah 1.594 jiwa dan sampel sebanyak 94 jiwa. Teknik penarikan sampel yang digunakan yaitu Purpossive Sampling. Tipe penelitian ini adalah deskriptif kuantitatif. Teknik pengumpulan data adalah observasi, wawancara, penelitian pustaka dan kuesioner. Teknik analisis data menggunakan statistik. Hasil penelitian menunjukkan bahwa kualitas jasa pelayanan dengan rata-rata persentase $58 \%$ kurang puas, terdiri dari tangibles (bukti fisik) $75 \%$ puas, reliability (kehandalan) $54 \%$ kurang puas, responsiveness (daya tanggap) $47 \%$ kurang puas, assurance (jaminan) $58 \%$ kurang puas, emphaty (empati) $58 \%$ kurang puas. Kepuasan pasien dengan rata-rata persentase $66 \%$ puas, terdiri dari sikap pendekatan staf pada pasien $54 \%$ kurang puas, kualitas perawatan yang diterima oleh pasien $53 \%$ kurang puas, prosedur administrasi $62 \%$ puas, waktu menunggu $78 \%$ puas, fasilitas umum yang lain $85 \%$ sangat puas, fasilitas ruang inap $75 \%$ puas dan hasil treatment atau hasil perawatan yang diterima oleh pasien $55 \%$ kurang puas. Faktor-faktor yang memengaruhi kualitas jasa pelayanan terhadap kepuasan pasien rawat inap di Puskesmas Lancirang Kecamatan Pitu Riawa Kabupaten Sidenreng Rappang yaitu layanan yang diharapkan dan layanan yang diterima $51 \%$ kurang puas.
\end{abstract}

Kata kunci : Kepuasan Masyarakat dan Kualitas Jasa Pelayanan

\begin{abstract}
This study aims to determine the quality of service to inpatient satisfaction and the factors that influence the quality of service to inpatient satisfaction at the Lancirang Health Center, Pitu Riawa District, Sidenreng Rappang Regency. The population of this study was 1,594 people and a sample of 94 inhabitants. The sampling technique used is Purpossive Sampling. This type of research is quantitative descriptive. Data collection techniques are observation, interviews, library research and questionnaires. Data analysis techniques use statistics. The results showed that the service quality with an average percentage of $58 \%$ less satisfied, consisting of tangibles (physical evidence) $75 \%$ satisfied, reliability (reliability) $54 \%$ less satisfied, responsiveness (responsiveness) $47 \%$ less satisfied, assurance (guarantee) $58 \%$ less satisfied, empathy (empathy) $58 \%$ less satisfied. Patient satisfaction with an average percentage of $66 \%$ satisfied, consisting of the attitude of the staff approach to patients $54 \%$ less satisfied, the quality of care received by patients $53 \%$ less satisfied, administrative procedures $62 \%$ satisfied, waiting time $78 \%$ satisfied, other public facilities $85 \%$ are very satisfied, inpatient facilities $75 \%$ satisfied and the results of treatment or treatment received by patients 55\% less satisfied. Factors that influence the quality of services to inpatient satisfaction at the Lancirang Health Center, Pitu Riawa District, Sidenreng Rappang Regency are expected services and services received by $51 \%$ less satisfied.
\end{abstract}

Keywords: Community Satisfaction and Quality of Service 


\section{A. PENDAHULUAN}

Berdasarkan Undang-Undang Nomor 36 Tahun 2009 tentang Kesehatan bahwa kesehatan adalah keadaan sejahtera dari badan, jiwa dan sosial yang memungkinkan setiap orang-orang untuk hidup produktif secara sosial dan ekonomi. Untuk mencapai tujuan tersebut ditetapkan bahwa setiap manusia mempunyai hak dan kewajiban yang sama atas pemeliharaan kesehatan juga penyediaan dana dari berbagai sumber. Untuk dapat mewujudkan keadaan sehat tersebut, banyak hal yang perlu dilakukan, salah satu diantaranya yang dinilai mempunyai peranan yang cukup penting adalah menyelenggarakan pelayanan kesehatan (Ramlan, 2017:220). Penyelenggaraan pelayanan kesehatan untuk masyarakat di tingkat dasar di Indonesia adalah melalui Pusat Kesehatan Masyarakat (Puskesmas) yang merupakan unit organisasi fungsional Dinas Kesehatan Kabupaten/Kotamadya dan diberi tanggung jawab sebagai pengelola kesehatan bagi masyarakat tiap wilayah kecamatan dari kabupaten/ kotamadya bersangkutan. Pemerintah menyelenggarakan pelayanan kesehatan mulai dari pelayanan kesehatan primer di tingkat Pusat Kesehatan Masyarakat (Puskesmas), pelayanan kesehatan sekunder di tingkat pelayanan rumah sakit dengan pelayanan spesialis, dan pelayanan kesehatan tertier yaitu rumah sakit dengan pelayanan sub spesialis.

Puskesmas sebagai unit pelayanan kesehatan primer merupakan salah satu pelayanan publik terdepan Pemerintah Kabupaten/Kota. Dalam lampiran Keputusan Menteri Kesehatan Republik Indonesia Nomor 128 Tahun 2004 tentang kebijakan dasar puskesmas disebutkan bahwa puskesmas adalah unit pelaksana teknis dinas kesehatan Kabupaten/Kota yang bertanggung jawab menyelenggarakan pelayanan kesehatan tingkat pertama secara menyeluruh, terpadu, dan berkesinambungan (Keputusan Menteri Kesehatan RI, 2004). Tujuan pembangunan kesehatan adalah meningkatkan kesadaran, kemauan dan kemampuan hidup sehat bagi setiap orang agar terwujud derajat kesehatan masyarakat yang optimal melalui terciptanya masyarakat bangsa dan negara yang ditandai penduduk dalam lingkungan sehat dan dengan perilaku hidup yang sehat, serta memiliki kemampuan untuk menjangkau layanan kesehatan yang bermutu dan berkualitas secara adil dan merata sesuai dengan kebijaksanaan umum dan strategi pembangunan kesehatan. Pada era globalisasi, dinamika kehidupan dunia usaha semakin keras dan ketat termasuk di bidang layanan kesehatan, dalam hal ini puskesmas, dengan makin tingginya tingkat pendidikan dan keadaan sosial ekonomi masyarakat, maka kebutuhan dan tuntutan masyarakat akan kesehatan tampak makin meningkat pula, untuk dapat memenuhi kebutuhan dan tuntutan tersebut, tidak ada upaya lain yang dapat dilakukan, kecuali menyelenggarakan layanan kesehatan yang sebaik - baiknya.

Sebagai lembaga kesehatan yang bermisi meningkatkan derajat kesehatan masyarakat, puskesmas telah berperan dalam memelihara dan meningkatkan derajat kesehatan masyarakat. Kepercayaan yang diberikan masyarakat dan pemerintah terhadap puskesmas tersebut adalah sebuah kehormatan sekaligus amanat dan tugas berat yang harus dipikul dengan sungguhsungguh dan penuh keikhlasan, terlebih dengan perkembangan ilmu dan teknologi dalam bidang kesehatan maka puskesmas dituntut lebih keras lagi berusaha dan meningkatkan profesionalisme dalam bekerja khususnya dalam memberikan pelayanan kesehatan kepada para pasiennya. Sebagai ujung tombak pelayanan dan pembangunan kesehatan di Indonesia, maka puskesmas perlu mendapatkan perhatian terutama berkaitan dengan kualitas pelayanan kesehatan puskesmas sehingga dalam hal ini puskesmas dituntut untuk selalu meningkatkan profesionalisasi dari para pegawainya serta meningkatkan fasilitas atau sarana kesehatannya untuk memberikan kepuasan kepada masyarakat pengguna jasa layanan kesehatan.

Layanan yang telah diterapkan di puskesmas yaitu dengan memberikan Senyum, Salam, Sapa, Sopan dan Santun (5 S) kepada setiap pasien yang datang ke puskesmas, memberikan pelayanan pemeriksaan yang baik pada setiap pasien yang datang berobat, sehingga memberikan kesan yang akrab dan nyaman serta tidak menimbulkan rasa kekhawatiran bagi pasien terhadap penyakit yang diderita serta berusaha memberikan pengobatan yang terbaik terhadap penyakit pasien, memberi 
layanan secara tepat dan cepat kepada setiap pasien.

Pelayanan yang berkualitas tentu saja tidak sebatas senyum ramah dari para pegawai puskesmas saja, melainkan lebih dari itu. Menurut Parasuraman, Zeithaml, dan Berry dalam Lupiyoadi (2013:216) terdapat lima dimensi utama yang relevan untuk menjelaskan kualitas pelayanan yang dikenal dengan service quality (servqual) yaitu, tangibe (bukti fisik), reliability (kehandalan), responsiveness (daya tanggap), assurance (jaminan), dan emphaty (empati). Kelima dimensi kualitas pelayanan tersebut merupakan kunci utama untuk meningkatkan kepuasan pasien.

Adanya bentuk layanan kesehatan yang diberikan oleh puskesmas diharapkan pasien akan dapat memberikan penilaian tersendiri terhadap puskesmas tersebut. Jika layanan yang diberikan sesuai dengan yang dikehendaki, maka pasien akan puas. Kepuasan adalah perasaan senang atau kecewa seseorang yang muncul setelah membandingkan kinerja (hasil) produk yang dipikirkan terhadap kinerja (atau hasil) yang diharapkan. Jika kinerja dibawah harapan, itu berarti pelanggan tidak puas. Jika itu yang terjadi maka akan menyebabkan kehilangan minat pasien untuk berobat. Hal ini akan menyebabkan pasien mempunyai image negatif terhadap puskesmas tersebut, dan akan mengakibatkan kurangnya minat pasien untuk melakukan pengobatan di puskesmas.

Fungsi layanan kepada masyarakat terkait dengan peran pemerintah sebagai bentuk dalam pemenuhan kepentingan masyarakat, layanan yang berkualitas merupakan tuntutan baik eksternal maupun internal. Secara eksternal layanan merupakan kemutlakan didalam arus globalisasi yang mampu menenggelamkan elemen-elemen yang tidak mampu tampil bersaing karena kapasitas yang tidak memenuhi kualifikasi persaingan global.

Layanan prima menjadi tuntutan masyarakat sejalan dengan peningkatan kebutuhan dan kesadaran dalam kehidupan bernegara dan bermasyarakat sebagai imbas dari kemajuan teknologi informasi. Kualitas yang tinggi merupakan tuntutan, tidak hanya dalam kegiatan bisnis namun juga dalam kegiatan layanan lembaga pemerintahan yang resisten terhadap tuntutan kualitas layanan publik.
Puskesmas Lancirang merupakan salah satu unit Pusat Kesehatan Masyarakat yang ada di Kabupaten Sidenreng Rappang, yang disediakan oleh pemerintah untuk memenuhi kebutuhan kesehatan masyarakat di Kecamatan Pitu Riawa. Peningkatan kualitas layanan yang baik tidak harus hanya berasal dari sudut pandang Puskesmas Lancirang Sidenreng Rappang saja, tetapi harus pula berasal dari sudut pandang pasien. Puskesmas Lancirang Sidenreng Rappang harus pula mengetahui keinginan dan kebutuhan pasien. Dengan meningkatnya kualitas layanan maka diharapkan kepuasan pasien juga akan meningkat dan loyalitas pasien akan dapat tercipta.

Berdasarkan uraian di atas, maka peneliti tertarik meneliti tentang "Kualitas Jasa Pelayanan terhadap Kepuasan Pasien Rawat Inap di Puskesmas Lancirang Kecamatan Pitu Riawa Kabupaten Sidenreng Rappang" dengan tujuan untuk mengetahui kualitas jasa pelayanan terhadap kepuasan pasien rawat inap dan untuk mengetahui faktor-faktor yang memengaruhi kualitas jasa pelayanan terhadap kepuasan pasien rawat inap di Puskesmas Lancirang Kecamatan Pitu Riawa Kabupaten Sidenreng Rappang.

Kualitas merupakan suatu kondisi dinamis yang berhubungan dengan produk, jasa, manusia, proses dan lingkungan yang memenuhi atau melebihi harapan. Tjiptono (Kamaruddin, 2016:146) mengatakan bahwa kata "kualitas" mengandung banyak definisi dan makna. Beberapa contoh definisi yang kerap kali dijumpai antara lain:

a. Kesesuaian dengan persyaratan/tuntutan;

b. Kecocokan untuk pemakaian;

c. Perbaikan/penyempurnaan berkelanjutan;

d. Bebas dari kerusakan/cacat;

e. Pemenuhan kebutuhan pelanggan semenjak awal dan setiap saat;

f. Melakukan segala sesuatu secara benar semenjak awal;

g. Sesuatu yang bisa membahagiakan pelanggan.

Menurut Yoga (Kamaruddin, 2016:146), mengemukakan bahwa kualitas layanan sumber daya manusia yaitu kemampuan dalam menghasilkan sumber daya manusia yang mampu mengembangkan potensi diri dan organisasinya dalam melaksanakan tugas untuk mencapai tujuan. Indikator mengacu kepada tujuh bentuk pelayanan publik dari Yoga, yaitu: 
a) Sederhana yaitu penerapan pelayanan yang sesuai dengan prosedur/tata cara pelayanan yang diselenggarakan secara mudah, lancar, cepat, tidak berbelit-belit, mudah dipahami, dan mudah dilaksanakan oleh publik yang menerima pelayanan.

b) Jelas dan pasti yaitu pelayanan yang mencakup prosedur/tata cara pelayanan, persyaratan teknis maupun administratif, unit kerja dan pejabat yang berwewenang dan bertanggung jawab serta sesuai jadwal waktu penyelesaian pelayanan.

c) Keamanan yaitu proses hasil pelayanan yang memberikan rasa aman dan memiliki kepastian hukum bagi publik.

d) Terbuka yaitu pelayanan yang sesuai dengan prosedur/tata cara, persyaratan, rincian tarif/biaya dan proses pelayanan yang ditransformasikan secara terbuka agar mudah diketahui oleh publik, diminta maupun tidak diminta.

e) Efisien yaitu pelayanan yang dibatasi pada hal-hal yang berkaitan langsung dengan pencapaian sasaran pelayanan dengan memperhatikan keterpaduan antara persyaratan dengan pelayanan yang diberikan.

f) Ekonomis yaitu pengenaan biaya pelayanan yang ditetapkan secara wajar dengan memperhatikan nilai layanan yang diberikan, kondisi dan kemampuan publik serta sesuai dengan ketentuan peraturan perundang-undangan yang berlaku.

g) Keadilan yaitu pelaksanaan pelayanan publik yang dapat diselesaikan dalam kurun waktu yang telah ditentukan dan tidak membeda-bedakan antara publik yang satu dengan publik yang lainnya sebagai pengguna layanan.

Melalui serangkaian penelitian terhadap berbagai macam industri jasa menurut Parasuraman, Zeithaml, dan Berry dalam Fandy Tjiptono (2011:196) berhasil mengidentifikasi sepuluh dimensi pokok kualitas jasa :

1) Reliabilitas meliputi sikap konsistensi terhadap kinerja (performance) sehingga memiliki sifat dapat dipercaya (dependability).

2) Responsivitas atau daya tanggap, yaitu kesediaan dan kesiapan para karyawan untuk membantu para pelanggan dan menyampaikan jasa secara cepat.

3) Kompetensi, yaitu penguasaan keterampilan dan pengetahuan yang dibutuhkan agar dapat menyampaikan jasa sesuai dengan kebutuhan pelanggan.

4) Akses, meliputi kemudahan untuk dihubungi atau ditemui (approachability) dan kemudahan kontak.

5) Kesopanan (courtesy), meliputi sikap santun, respek, atensi, dan keramahan para karyawan.

6) Komunikasi, artinya menyampaikan informasi kepada pelanggan dalam bahasa yang mudah mereka pahami, serta selalu mendengarkan saran dan keluhan pelanggan.

7) Kredibilitas, yaitu sifat jujur dan dapat dipercaya. Kredibilitas mencangkup nama perusahaan, reputasi perusahaan, karakter pribadi karyawan kontak, dan interaksi dengan pelanggan (hard selling versus soft selling approach).

8) Keamanan (security), yaitu bebas dari bahaya, risiko atau keraguraguan.

9) Kemampuan memahami pelanggan, yaitu berupaya memahami pelanggan dan kebutuhan spesifik mereka, memberikan perhatian individual, dan mengenal pelanggan regular.

10) Bukti fisik (tangibles), meliputi penampilan fasilitas fisik, peralatan, personil, dan bahan-bahan komunikasi perusahaan (seperti kartu bisnis, kop surat, dan lain-lain).

Parasuraman, Zeithaml, dan Berry dalam Lupiyoadi (2013:216), menemukan adanya overlapping diantara beberapa dimensi diatas. Oleh sebab itu, mereka menyederhanakan sepuluh dimensi tersebut menjadi lima dimensi pokok. Dengan demikian, terdapat lima dimensi utama service quality (SERVQUAL), yaitu :

1) Tangibles (Bukti fisik). Menurut Lupiyoadi dalam bukunya Manejemen Pemasaran Jasa (2013:216), Bukti fisik adalah kemampuan suatu perusahaan dalam menunjukan eksistensinya kepada pihak eksternal. Penampilan dan kemampuan sarana dan prasarana fisik perusahaan yang dapat diandalkan keadaan lingkungan sekitarnya merupakan bukti nyata dari pelayanan yang diberikan oleh pemberi jasa. hal ini meliputi fasilitas fisik (contoh: gedung, gudang, dan lain-lain), perlengkapan, dan peralatan yang digunakan (teknologi), serta penampilan pegawainya. Bukti fisik berkenaan dengan penampilan fisik fasilitas layanan, 
peralatan, sumberdaya manusia, dan materi komunikasi perusahaan. (Tjiptono,2012:175). Adapun indikator tangible adalah sebagai berikut;
a) Kelengkapan alat yang dimiliki puskesmas.
b) Kebersihan gedung.
c) Penampilan Karyawan.
d) Ketersediaan tempat parkir yang luas.

2) Reliability (kehandalan). Kehandalan yaitu kemampuan perusahaan untuk memberikan pelayanan sesuai dengan yang dijanjikan secara akurat dan terpercaya. Kinerja harus sesuai dengan harapan pelanggan yang berarti ketepatan waktu, pelayananan yang sama untuk semua pelanggan tanpa kesalahan, sikap yang simpatik, dan dengan akurasi yang tinggi (Lupiyoadi, 2013:217). Keandalan merupakan kemampuan perusahaan untuk memberikan pelayanan yang dijanjikan dengan akurat sejak pertama kali. (Tjiptono, 2012:174). Indikator reliability adalah sebagai berikut;

a) Perhatian sungguh-sungguh terhadap pasien.

b) Kesungguhan memperhatikan pasien yang mendapat masalah.

c) Keakuratan penanganan masalah.

d) Ketepatan waktu pelayanan sesuai yang dijanjikan.

3) Responsiveness (Daya tanggap). Menurut Lupiyoadi (2013:217) daya tanggap adalah kemampuan perusahaan untuk memberikan pelayanan yang cepat (responsif) dan tepat kepada pelanggan, dengan penyampaian informasi yang jelas. Daya tanggap berkenaan dengan kesediaan dan kemampuan penyedia layanan untuk membantu para pelanggan dan merespon permintaan mereka dengan segera. (Tjiptono, 2012:175). Indikator Responsiveness) adalah sebagai berikut;

a) Kesediaan karyawan memberikan pelayanan dengan cepat.

b) Kesediaan membantu kesulitan yang dihadapi pasien.

c) Keluangan waktu menanggapi permintaan pasien.

d) Kejelasan dalam menyampaikan informasi jasa.

4) Assurance (Jaminan). Menurut Lupiyoadi (2013:217) Jaminan (assurance), yaitu pengetahuan, kesopan-santunan, dan kemampuan para pegawai perusahaan untuk menumbuhkan rasa percaya para pelanggan terhadap perusahaan. pengetahuan dan kesopanan para karyawan serta kemampuan mereka menumbuhkan rasa percaya (trust) dan kepercayaan pelanggan (confidence). (Tjiptono, 2012:175). Indikator Assurance (jaminan) adalah sebagai berikut;

a) Kompetensi karyawan.

b) Rasa percaya pasien terhadap karyawan.

c) Kesabaran karyawan dalam memberikan layanan.

d) Dukungan dari puskesmas kepada karyawan untuk melaksanakan tugasnya.

5) Emphaty (Empati). Menurut Lupiyoadi (2013:217), Empati yaitu memberikan perhatian yang tulus dan bersifat individual atau pribadi yang diberikan kepada para pelanggan dengan berupaya memahami keinginan mereka. Hal ini mengharapkan bahwa suatu perusahaan memiliki pengertian dan pengetahuan tentang pelanggan, memahami kebutuhan pelanggan secara spesifik, serta memiliki waktu pengoperasian yang nyaman bagi pelanggan. Empati merupakan kemampuan memahami masalah pelanggannya bertindak demi kepentingan pelanggan, dan memberikan perhatian personal kepada para pelanggan (Tjiptono, 2012:175). Indikator Emphaty adalah sebagai berikut;

a) Perhatian secara personal kepada pasien.

b) Pemahaman karyawan akan kebutuhan dan perasaan pasien.

c) Kesungguhan puskesmas terhadap kepentingan pasien.

d) Kesesuaian jam kerja dengan kesibukan pasien.

Dua faktor utama yang mempengaruhi kualitas jasa pelayanan, yaitu, layanan yang diharapkan dan layanan yang diterima. Hal ini berarti ada dua faktor utama yang mempengaruhi kualitas jasa yaitu jasa yang diharapkan dan jasa yang dipersepsikan. Bila jasa yang diterima atau yang dirasakan sesuai dengan yang diharapkan, maka kualitas jasa dipersepsikan baik atau memuaskan. Jika jasa yang diterima melebihi harapan pelanggan, maka kualitas jasa dipersepsikan sebagai kualitas jasa yang ideal. Akan tetapi jika jasa yang diterima lebih rendah dari pada yang diharapkan, maka kualitas jasa sangat bergantung pada 
kemampuan penyedia jasa kepada konsumen secara kontinue dan konsisten. Parasuraman, Zeithaml, dan Berry (Pratiwi, 2017:228-229)

Moenir (Kamaruddin, 2016:75) mengemukakan bahwa pelayanan umum adalah kegiatan yang dilakukan oleh seseorang atas sekelompok orang dengan landasan faktor material melalui sistem, prosedur dan metode tertentu dalam rangka usaha memenuhi kepentingan orang lain sesuai dengan haknya. Pelayanan hakikatnya adalah serangkaian kegiatan, karena itu ia merupakan proses. Sebagai proses, pelayanan berlangsung secara rutin dan berkesinambungan, meliputi seluruh kehidupan orang dalam masyarakat. Selanjutnya Moenir mengemukakan bahwa pelaksanaan pelayanan dapat diukur, oleh karena itu dapat ditetapkan standar yang baik dalam hal waktu yang diperlukan maupun hasilnya. Dengan adanya standar manajemen dapat merencanakan, melaksanakan, mengawasi dan mengevaluasi kegiatan pelayanan, agar supaya hasil akhir memuaskan pada pihakpihak yang mendapatkan layanan.

Menurut Fitzsimmons dalam Kamaruddin (2016:75) mengatakan bahwa "customer satisfaction with service quality can be defined perception of received with expectation of service desired" (maksudnya rasa puas orang yang memerlukan pelayanan bisa diartikan dengan memperbandingkan bagaimana pandangan antara pelayanan yang diterima dengan harapan pelayanan yang diharapkan). Jadi dalam pelayanan pemerintah, rasa puas masyarakat terpenuhi bila apa yang diberikan oleh pemerintah kepada mereka sesuai dengan apa yang mereka harapkan. Ketika masyarakat menghendaki pembuatan kartu tanda penduduk, izin mengemudi, izin mendirikan bangunan, dan lain-lain dikerjakan dalam kurun waktu yang singkat, dengan biaya relatif murah serta mutu yang baik. Jadi, bila yang mereka terima adalah pembuatannya dikerjakan berlarut-larut, biaya yang dikeluarkan cukup tinggi dan tidak transparan, serta kemudian mutu surat izin tersebut buruk, tidak bisa dibaca, salah tanggal dan nama, atau keliru lokasi, maka masyarakat tidak puas, jadi, yang namanya pelayanan terdiri dari tiga unsur pokok, yaitu sebagai berikut:

a. Biayanya relatif harus lebih rendah, b. Waktu untuk mengerjakan relatif cepat, dan

c. Mutu yang diberikan relatif lebih bagus.

Kepuasan menurut Kamus Bahasa Indonesia adalah puas: merasa senang: perihal (yang bersifat puas, kesenangan, kelegaan dan sebagainya). Kepuasan dapat diartikan sebagai perasaan puas, rasa senang dan kelegaan seseorang dikarenakan mengkonsumsi suatu produk atau jasa untuk mendapatkan pelayanan suatu jasa (Pratiwi, 2017:223). Oliver (Pratiwi, 2017:223) mendefinisikan kepuasan sebagai tingkat perasaan seseorang setelah membandingkan kinerja atau hasil yang dirasakannya dengan harapannya. Tingkat kepuasan merupakan fungsi dari perbedaan antara kinerja yang dirasakan dengan harapan. Apabila kinerja dibawah harapan, maka pelanggan akan kecewa. Bila kinerja sesuai harapan, maka pelanggan akan puas. Sedangkan bila kinerja melebihi harapan, pelanggan akan merasa sangat puas.

Menurut Griffith (Pratiwi, 2017:224) ada beberapa aspek-aspek yang mempengaruhi perasaan puas pada seseorang, yaitu:

a. Sikap pendekatan staf pada pasien yaitu sikap staf terhadap pasien ketika pertama kali datang di rumah sakit.

b. Kualitas perawatan yang diterima oleh pasien yaitu apa saja yang telah dilakukan oleh pemberi layanan kepada pasien, seberapa pelayanan perawatan yang berkaitan dengan proses kesembuhan penyakit yang diderita pasien dan kelangsungan perawatan pasien selama berada di rumah sakit.

c. Prosedur administrasi yaitu berkaitan dengan pelayanan administrasi pasien dimulai masuk rumah sakit selama perawatan berlangsung, sampai keluar rumah sakit.

d. Waktu menunggu yang berkaitan dengan waktu yang diperbolehkan untuk berkunjung maupun untuk menjaga dari keluarga maupun dari orang lain dengan memperhatikan ruang tunggu yang memenuhi standar-standar rumah sakit antara lain: ruang tunggu yang nyaman, tenang.

e. Fasilitas umum yang lain seperti kualitas pelayanan berupa makanan dan minuman, privasi dan kunjungan. Fasilitas ini berupa bagaimana pelayanan terhadap pemenuhan kebutuhan pasien seperti makanan dan minuman yang disediakan. 
f. Fasilitas ruang inap untuk pasien yang harus rawat. Fasilitas ruang inap ini disediakan berdasarkan permintaan pasien mengenai ruang rawat inap yang dikehendakinya.

g. Hasil treatment atau hasil perawatan yang diterima oleh pasien yaitu perawatan yang berkaitan dengan kesembuhan penyakit pasien baik berupa operasi, kunjungan dokter atau perawat.

\section{B. METODE PENELITIAN}

Penelitian yang digunakan adalah deskriptif dengan menggunakan pendekatan kuantitatif yaitu yang bertujuan, untuk menggambarkan permasalahan secara sistemis, faktual dan aktual yang terjadi di lokasi penelitian yaitu menjelaskan tentang kualitas jasa kesehatan terhadap kepuasan pasien di Kecamatan Pitu Riawa Kabupaten Sidenreng Rappang.

Populasi dalam penelitian ini adalah keseluruhan jumlah masyarakat yang melakukan pelayanan di Puskesmas Lancirang Kecamatan Pitu Riawa Kabupaten Sidenreng Rappang pada bulan Desember 2018 sebanyak 1.594 jiwa. Jadi, dari 1.594 jumlah populasi, maka jumlah sampel adalah 94 jiwa sedangkan teknik penarikan sampel yang digunakan adalah Nonprobability Sampling.

Teknik pengumpulan data terdiri dari observasi, wawancara, penelitian pustaka (library research) dan kuesioner. Teknik analisis data dalam penelitian kuantitatif menggunakan statistic. Skala pengukuran data dilakukan dengan lebih menekankan pada pengukuran sikap, pendapat, dan persepsi seseorang tentang fenomena sosial yang menggunakan Skala Likert.

\section{HASIL DAN PEMBAHASAN}

Puskesmas Lancirang adalah Fasilitas Kesehatan Tingkat Pertama (FKTP) yang bertanggung jawab atas kesehatan masyarakat di wilayah kerjanya pada bagian wilayah Kecamatan Pitu Riawa Kabupaten Sidenreng Rappang. Puskesmas lancirang berada di jalan poros Provinsi di Kelurahan Ponrangae. Wilayah kerja Puskesmas Lancirang Kecamatan Pitu Riawa ada 2 Kelurahan dan 4 Desa, yang berbatasan dengan:

Sebelah Timur : Kecamatan Dua Pitue
p-ISSN 2302-0970

e-ISSN 2723-0201

Sebelah Barat : Kecamatan Watang Sidenreng

Sebelah Selatan: Kabupaten Wajo

Sebelah Utara : Kecamatan Panca Rijang

Wilayah kerja Puskesmas Lancirang dengan luas $3.800 \mathrm{~km}^{2}$. Kondisi topografi wilayah kerja Puskesmas Lancirang dengan keadaan tanah datar $100 \%$ dengan ketinggian permukaan laut $<500$.

1. Kualitas Jasa Pelayanan di Puskesmas Lancirang

a. Tangibles (bukti fisik), rata-rata skor 3.76 , rata-rata persentase $75 \%$ kategori puas.

b. Reliability (kehandalan), rata-rata skor 2.68 , rata-rata persentase $54 \%$ kategori kurang puas.

c. Responsiveness (daya tanggap), ratarata skor 2.34, rata-rata persentase $47 \%$ kategori kurang puas.

d. Assurance (jaminan), rata-rata skor 2.9, rata-rata persentase $58 \%$ kategori kurang puas.

e. Emphaty (empati), rata-rata skor 2.89, rata-rata persentase $58 \%$ kategori kurang puas

Akumulasi hasil rata-rata persentase dari 5 indikator pertanyaan pada variabel kualitas jasa pelayanan di atas, maka didapatkan hasil rata-rata persentase $58 \%$. Adapun keseluruhan frekuensi adalah sebesar 1371.

2. Kepuasan Pasien di Puskesmas Lancirang

a. Sikap pendekatan staf pada pasien, rata-rata skor 2.7 , rata-rata persentase $54 \%$ kategori kurang puas.

b. Kualitas perawatan yang diterima oleh pasien, rata-rata skor 2.64 , rata-rata persentase $53 \%$ kategori kurang puas.

c. Prosedur administrasi, rata-rata skor 3.08 , rata-rata persentase $62 \%$ kategori puas.

d. Waktu menunggu, rata-rata skor 3.91, rata-rata persentase $78 \%$ kategori puas.

e. Fasilitas umum yang lain, rata-rata skor 4.23 , rata-rata persentase $85 \%$ kategori sangat puas.

f. Fasilitas ruang inap, rata-rata skor 3.76, rata-rata persentase $75 \%$ kategori puas.

g. Hasil treatment atau hasil perawatan yang diterima oleh pasien, rata-rata 
skor 2.75 , rata-rata persentase $55 \%$ kategori kurang puas.

Dengan mengakumulasi hasil rata-rata persentase dari 7 indikator pertanyaan pada variabel kepuasan pasien di atas, maka didapatkan hasil rata-rata persentase $66 \%$. Adapun keseluruhan frekuensi adalah sebesar 2172.

3. Faktor-faktor yang memengaruhi kualitas jasa pelayanan terhadap kepuasan pasien di Puskesmas Lancirang Kecamatan Pitu Riawa Kabupaten Sidenreng Rappang yaitu layanan yang diharapkan, dan layanan yang diterima, rata-rata skor 2.57 , rata-rata persentase $51 \%$ mempengaruhi.

Berdasarkan penelitian terdahulu dengan judul "Analisis Kualitas Pelayanan terhadap Kepuasan Pelanggan (Studi Kasus: Pasien Rawat Inap Rumah Sakit Umum Daerah Andi Makassau Kota Parepare)" (Pratiwi Ramlan, 2017: KNAPPPTMA ke-6). Dengan hasil penelitian yaitu pada tingkat kepercayaan 95\%, dimensi-dimensi kualitas pelayanan seperti bukti langsung (tangible), keandalan (reliability), daya tanggap (responsiveness), jaminan (assurance) dan perhatian (emphaty) berpengaruh secara simultan dan signifikan terhadap kepuasan pasien. Hal ini menunjukkan bahwa penelitian terdahulu tidak sejalan dengan penelitian ini, dengan membandingkan persentase kualitas jasa pelayanan $58 \%$ dan kepuasan pasien 66\%. Dengan alasan bahwa tingkat kepercayaan pasien terhadap kualitas jasa pelayanan yang diberikan oleh staf belum sesuai dengan harapan masyarakat. Meskipun jika dilihat persentase kepuasan masyarakat berada dalam kategori puas, akan tetapi terdapat beberapa item didalamnya yang tetap perlu dibenahi.

Pada penelitian ini, variabel kualitas jasa pelayanan berupa reliability (kehandalan), responsiveness (daya tanggap), assurance (jaminan), empathy (empati) merupakan indikator yang menjadi perhatian dan dapat lebih difokuskan karena tanggapan miring masyarakat terhadap komponen ini. Begitu pula pada variabel kepuasan pasien, indikator sikap pendekatan staf pada pasien, kualitas perawatan yang diterima oleh pasien, dan hasil treatment atau hasil perawatan yang diterima oleh pasien yang lebih disorot.

Maka ditarik kesimpulan bahwa, perlu ditinjau kembali mengenai dimensi-dimensi kualitas jasa pelayanan yang diberikan oleh staf atau pegawai kepada masyarakat sehingga perlu dilakukan koreksian dan perbaikan kualitas jasa pelayanan di Puskesmas Lancirang.

\section{KESIMPULAN}

1. Kualitas jasa pelayanan dengan rata-rata persentase $58 \%$ kurang puas, terdiri dari tangibles (bukti fisik) $75 \%$ puas, reliability (kehandalan) $54 \%$ kurang puas, responsiveness (daya tanggap) $47 \%$ kurang puas, assurance (jaminan) $58 \%$ kurang puas, emphaty (empati) 58\% kurang puas. Kepuasan pasien dengan rata-rata persentase $66 \%$ puas, terdiri dari sikap pendekatan staf pada pasien $54 \%$ kurang puas, kualitas perawatan yang diterima oleh pasien $53 \%$ kurang puas, prosedur administrasi $62 \%$ puas, waktu menunggu $78 \%$ puas, fasilitas umum yang lain $85 \%$ sangat puas, fasilitas ruang inap $75 \%$ puas dan hasil treatment atau hasil perawatan yang diterima oleh pasien $55 \%$ kurang puas.

2. Faktor-faktor yang memengaruhi kualitas jasa pelayanan terhadap kepuasan pasien rawat inap di Puskesmas Lancirang Kecamatan Pitu Riawa Kabupaten Sidenreng Rappang yaitu layanan yang diharapkan dan layanan yang diterima $51 \%$ kurang puas.

\section{E. REFERENSI}

BUKU-BUKU:

Jamaluddin, Ahmad. 2015. Metode Penelitian Administrasi Publik Teori dan Aplikasinya. Yogyakarta. Gava Media.

Buchory, Acmad Herry \& Saladin Djaslim. (2010). Manajemen Pemasaran, Edisi Pertama. Bandung. Linda Karya.

Hasbar, Mustafa. 2014. Menguak Perilaku Organisasi Sektor Publik Antara Teori dan Aplikasi. Yogyakarta. Ombak.

Kotler, Philip and Kevin Lane Keller. 2016. Marketing Management 15. Pearson Education, Inc.

Lupiyoadi, Rambat. 2013. Manajemen Pemasaran Jasa, Edisi Ketiga. Jakarta. Salemba Empat.

Mustafa, Delly. 2012. Perilaku Birokrasi: Diantara Pelayan dan Dilayani. Makassar. Fahmis Pustaka.

Nasir, Moh. 2005. Metode Penelitian. Jakarta. Ghalia Indonesia. 
Kamaruddin, Sellang. 2016. Administrasi dan Pelayanan Publik, Antara Teori dan Aplikasi. Penerbit Ombak. Yogyakarta.

Tjiptono, Fandy. 2011. Pemasaran Jasa. Malang. Bayumedia. 2012. Service Management Mewujudkan Layanan Prima, Edisi Kedua. Yogyakarta. Penerbit Andi.

\section{Dokumen-dokumen :}

Keputusan Menteri Kesehatan Republik Indonesia nomor 128 tahun 2004 tentang Kebijakan Dasar Puskesmas.

Data Puskesmas Lancirang Kecamatan Pitu Riawa Kabupaten Sidenreng Rappang, Bagian Tata Usaha (Desember, 2018).

Undang-Undang Nomor 36 Tahun 2009 tentang Kesehatan.

JURNAL-JURNAL:

Ansar. 2012. Jurnal Ilmu Administrasi dan IImu Sosial. Edisi: Vol.1 No.II JuliOktober 2012 ISSN: 2252-9705. Makassar. Universitas Islam Makassar.

Gamrin, Burhanuddin dan Joeharno. 2008. Faktor-faktor yang Memengaruhi Mutu Pelayanan Kesehatan di
p-ISSN 2302-0970

e-ISSN 2723-0201

Rumah

Sakit.

(Blog Joeharno.blogspot.com), diakses pada tanggal 13 Januari 2019, pukul 13.45 WITA.

Pratiwi, Ramlan. 2017. Analisis Kualitas Pelayanan Terhadap Kepuasan Pelanggan (Studi Kasus: Pasien Rawat Inap Rumah Sakit Umum Daerah Andi Makassau Kota Parepare. KNAPPPTMA ke-6. ISBN:978-602-50710-1-0. STISIP Muhammadiyah Rappang.

Sari, Etty Tuntas. 2003. Analisis Kualitas Jasa Pelayanan Kesehatan terhadap Kepuasan Pasien Rawat Inap di RSUD Wonogiri. Surakarta. Universitas Sebelas Maret.

Sahar. 2016. Peranan Pemerintah Desa terhadap Pengembangan Generasi Muda Desa Tonronge Kecamatan Baranti Kabupaten Sidenreng Rappang. STISIP Muhammadiyah Rappang.

Tuwu, Lahibu. 2012. Disertasi. Pengaruh Gaya Kepemimpinan, Pengembangan Karir, Motivasi Kerja terhadap Kinerja dan Kualitas Layanan Sumber Daya Manusia pada Pemerintah Daerah Kabupaten Buton. Program Pascasarjana UMI. Makassar. 